ORIGINAL ARTICLE

\title{
The diagnosis of borderline iron deficiency: results of a therapeutic trial
}

\author{
C M Wright, J Kelly, A Trail, K N Parkinson, G Summerfield
}

Arch Dis Child 2004;89:1028-1031. doi: 10.1136/adc.2003.047407

See end of article for authors' affiliations

......................

Correspondence to: CM Wright, Department of Child Health, University of Glasgow, Glasgow, UK; charlotte.wright@clinmed. gla.ac.uk

Revised version received 23 March 2004

Accepted for publication

31 March 2004

Background: Iron deficiency is common in early childhood and has been associated with developmental delay. It is not known how reliably markers of iron deficiency identify true iron deficiency, defined as a therapeutic response to oral iron.

Methods: The subjects were members of the Millennium Baby Study cohort. At age 13 months a venous blood sample was taken for mean cell volume (MCV), haemoglobin, mean cell haemoglobin (MCH), ferritin, and zinc protoporphyrin (ZPP). Children with abnormal values were offered treatment with oral iron and dietary modification, and re-sampled after 3 months.

Results: Samples were obtained for 462 children. All markers were moderately correlated with each other except ferritin. Treatment was offered to $147(32 \%)$ children with at least one abnormal value, of whom $126(86 \%)$ were re-sampled. Children with a haemoglobin or an $\mathrm{MCH}$ below the screening cut off, or with abnormal values for two or more of the remaining three measures, showed a large therapeutic response to iron, but isolated abnormalities of MCV, ZPP, or ferritin were not consistently associated with a response. Of the screened population $13 \%$ could be defined as iron deficient (abnormal haemoglobin or $\mathrm{MCH}$, or abnormal levels of two or more of the remaining three markers), but this was not strongly associated with any dietary, demographic, or anthropometric characteristic.

Conclusions: Low total or mean cell haemoglobin in isolation is a specific marker of iron deficiency, but other markers are only predictive when found in combination with other abnormal values.

1 on deficiency is one of the commonest nutrient deficiencies found in early childhood, which, as well as causing anaemia, has widely recognised neurodevelopmental effects. ${ }^{1}$ Iron deficiency may be related to the low iron content of early weaning foods and over-reliance on unmodified cows' milk. ${ }^{2}$ Previous studies have found high levels of anaemia (defined as a haemoglobin below $11 \mathrm{~g}$ ) in toddlers, particularly those of South Asian origin, ${ }^{3}$ but rates can vary widely. In two large population surveys, predominantly in Caucasians, the estimated rate of anaemia at 18 months varied from $12 \%^{4}$ to $20 \%{ }^{5}$ This discrepancy may be explained by the different sampling methods used, ${ }^{6}$ but it raises the question of whether a low haemoglobin is truly specific for iron deficiency. A low haemoglobin may also be insensitive, since neurodevelopmental effects have been described with iron deficiency even before the development of anaemia. ${ }^{7}$

There are many other potential markers of iron status which may be used in clinical practice. Markers not commonly used now are serum iron, which mainly reflects dietary iron consumption, and the total iron binding capacity, which has been largely superseded by serum ferritin as a measure of iron stores. The mean cell haemoglobin $(\mathrm{MCH})$ and mean cell volume (MCV) are characteristically reduced in iron deficiency and may drop before total haemoglobin. Zinc protoporphyrin (ZPP), an early product in the synthesis of haem, rises in iron deficiency, but is not commonly used. Survey work has now established the normal range for these values in healthy toddlers but found that their intercorrelation, though statistically significant, was fairly weak. ${ }^{4}$ What is not clear is whether an extreme value of any one marker indicates iron deficiency.

In the absence of a gold standard, the strongest indicator of iron deficiency is a therapeutic response to iron treatment. This study thus set out to examine the extent to which currently used markers of iron deficiency predict a therapeutic response to oral iron, with the hypothesis that a combination of markers would be a better predictor than haemoglobin alone.

\section{METHODS}

The subjects for this study were identified from within the Millennium Baby Study, a population based, prospective study of feeding and growth in early childhood, via parental questionnaires and a health check at age 13 months. Here weights and lengths of all children were measured and, where consent was obtained, a venous blood sample was taken for haemoglobin, MCV, and MCH using a Coulter STKS blood cell analyser (Coulter Electronics, Hialeah, FL), ferritin using an electrochemical luminescence immunoassay instrument (Roche Diagnostics, Indianapolis, IN), and ZPP using an Aviv ZP hematoflurometer (Aviv Biomedical, Lakewood, NJ). Ethical approval for the study was obtained from Gateshead LREC.

All children found to have an abnormal value for any one of the measures were offered treatment. The treatment thresholds (table 1) were chosen to accord generally with common clinical practice and to ensure that a reasonable proportion of children would fall below each threshold, as indicated by data for children of similar age in the National Diet and Nutrition Survey (NDNS). ${ }^{4}$ Treatment consisted of oral iron (Sytron (sodium feredetate), $1 \mathrm{ml} / \mathrm{kg}$ per day, in three doses) for 6 weeks, in two aliquots. Parents were also given free milk tokens for the duration of the trial, to encourage them to re-start formula milk, as well as a diet sheet listing foods rich in iron. The study nurses kept in contact with families by phone and supplied the second bottle of iron when required. Then 3 months after starting

Abbreviations: $\mathrm{MCH}$, mean cell haemoglobin; $M C V$, mean cell volume; NDNS, National Diet and Nutrition Survey; TRS, therapeutic response score; ZPP, zinc protoporphyrin 
Table 1 Blood results for whole cohort

\begin{tabular}{llllllr}
\hline Measure (unit) & Total & Median & Mean & Interquartile range & Screening threshold used & Number (\%) below threshold \\
\hline Haemoglobin $(\mathrm{g} / \mathrm{dl})$ & 461 & 12.1 & 12.20 & 11.7 to 12.8 & $<11$ & $28(6 \%)$ \\
MCV (fl) & 461 & 80.4 & 80.06 & 78.0 to 82.4 & $<75$ & $45(9 \%)$ \\
MCH (pg) & 461 & 27.5 & 27.34 & 24.6 to 28.3 & $<25$ & $29(6 \%)$ \\
Ferritin $(\mu \mathrm{g} / \mathrm{l})$ & 414 & 23.0 & 28.15 & 16.0 to 35.0 & $<10$ & $32(7 \%)$ \\
ZPP $(\mu \mathrm{mol} / \mathrm{mol}$ haem) & 461 & 67.0 & 71.87 & 57.0 to 77.0 & $>80$ & $108(23 \%)$ \\
& & & & & & $43(9 \%)$ \\
\hline
\end{tabular}

treatment, a follow up blood test was taken and all the measures were repeated.

\section{Analysis}

For each of the five measures the values before and after treatment were converted to standard deviation (SD) scores ([value-mean]/SD) where the mean and SD were those for that measure at the first screen of the whole cohort. Logged values were used for ferritin and ZPP. Change over time was then calculated for each variable by subtracting the earlier from the later score. A therapeutic response score (TRS) was then calculated by summing the changes in score for each measure. The TRS was not normally distributed, so comparisons between subgroups were made using a non-parametric test (Mann-Whitney).

Demographic information was collected at recruitment and used to dichotomise families into affluent (homeowner, car owner, and one or more employed parent) and deprived (one or more of: rented housing, no car, no employed parent). Information about milk feeding and age of weaning was also available from the parental questionnaires. Weights and heights were converted into SD scores compared to the UK 1990 growth reference. ${ }^{8} 9$

\section{RESULTS}

Of the 1029 subjects in the main cohort study, 846 (82\%) attended the health check and the parents of 495 of those babies agreed for blood to be taken. Samples were obtained and analysed for $462(45 \%)$ children at a mean (SD) age of 13.9 (1.1) months.

Of those supplying blood samples, $47 \%$ came from relatively deprived families compared to $54 \%$ in the cohort as a whole $\left(\mathrm{p}=0.017, \chi^{2}\right.$ test $)$; however, a similar proportion to the cohort as a whole were formula fed from birth (46\%) or breast fed for more than 4 months (18\%). Most children were drinking unmodified cows' milk at the time of screening, of whom $122(26 \%)$ had begun to do so before the age of 12 months. Only two children had previously taken oral iron, both more than 6 months before. Weaning information, available for $393(80 \%)$ infants, showed that 19\% had been weaned before 3 months and 356 (90\%) before 4 months.
Table 3 Changes in markers after treatment

\begin{tabular}{|c|c|c|c|c|}
\hline \multirow[b]{2}{*}{ Measure } & \multirow[b]{2}{*}{ Number } & \multirow{2}{*}{$\begin{array}{l}\begin{array}{l}\text { Change in } \\
\text { raw values }\end{array} \\
\text { Median }\end{array}$} & \multicolumn{2}{|c|}{$\begin{array}{l}\text { Change in standardised } \\
\text { values }\end{array}$} \\
\hline & & & Median & IQR \\
\hline $\begin{array}{l}\text { Haemoglobin } \\
(\mathrm{g} / \mathrm{dl})\end{array}$ & 126 & 0.00 & 0.00 & -0.5 to 0.71 \\
\hline MCV $(f l)$ & 126 & 0.40 & 0.24 & -0.25 to 0.60 \\
\hline $\mathrm{MCH}(\mathrm{pg})$ & 126 & 0.55 & 0.14 & -0.15 to 0.54 \\
\hline Ferritin ( $\mu \mathrm{g} / \mathrm{l})$ & 104 & 0.5 & 0.01 & -0.52 to 0.96 \\
\hline $\begin{array}{l}\text { ZPP }(\mu \mathrm{mol} / \mathrm{mol} \\
\text { haem) }\end{array}$ & 125 & -15.0 & -0.62 & -1.18 to 0.00 \\
\hline TRS* & 125 & - & 0.86 & -2.6 to 2.12 \\
\hline
\end{tabular}

*Sum of changes in standardised scores for $\mathrm{Hb}, \mathrm{MCV}, \mathrm{MCH}$, and ZPP. $I Q R$, interquartile range.

For most measures only 6-9\% of the children had any one value below the treatment threshold (table 1). However 108 (23\%) children had values of ZPP above $80 \mu \mathrm{mol} / \mathrm{mol}$ haem. All the markers correlated with each other moderately, except ferritin (table 2). At the time of the health check 108 (23\%) children were described as mildly unwell, while three children $(0.6 \%)$ had a fever. These children had significantly higher ferritin levels than the remainder (geometric mean unwell or fever 28.0, remainder 21.0; $\mathrm{p}=0.001, t$ test). ZPP levels were unaffected.

In total $147(32 \%)$ children had at least one abnormal value and were offered treatment. Milk tokens were issued to 125 families, but they tended to have difficulty persuading their children to re-start formula milk. At follow up 3 months later 126 families (86\%) attended for a repeat blood test. At least one bottle of oral iron ( 3 weeks treatment) had been accepted by 124 of these families, but 41 (33\%) did not accept the second bottle. Of these $31(76 \%)$ spontaneously reported that the iron had caused diarrhoea, as did $24(29 \%)$ of those who had the full course $\left(p<0.001, \chi^{2}\right.$ test $)$.

At follow up all measures tended to have improved (table 3), but there was a wide variation and the median change for any one variable was small. Paired ferritin values were only available for 104 (82\%) subjects and ferritin showed the weakest correlation with other values, so the TRS

Table 2 Intercorrelation of various markers in whole cohort

\begin{tabular}{|c|c|c|c|c|c|}
\hline & Haemoglobin & MCV & $\mathrm{MCH}$ & Log ferritin & $\log Z P P$ \\
\hline Haemoglobin & 1 & $\begin{array}{c}0.32 \\
p<0.001\end{array}$ & $\begin{array}{c}0.37 \\
p<0.001\end{array}$ & $\begin{array}{c}0.03 \\
p=0.543\end{array}$ & $\begin{array}{c}-0.24 \\
p<0.001\end{array}$ \\
\hline MCV & & 1 & $\begin{array}{c}0.83 \\
p<0.001\end{array}$ & $\begin{array}{c}0.17 \\
p<0.001\end{array}$ & $\begin{array}{l}-0.39 \\
p<0.001\end{array}$ \\
\hline $\mathrm{MCH}$ & & & 1 & $\begin{array}{c}0.16 \\
p=0.001\end{array}$ & $\begin{array}{l}-0.38 \\
p<0.001\end{array}$ \\
\hline Log ferritin & & & & 1 & $\begin{array}{l}-0.15 \\
p=0.003\end{array}$ \\
\hline Log ZPP & & & & & 1 \\
\hline
\end{tabular}


Table 4 Size of therapeutic response following abnormal values of different markers at first screen

\begin{tabular}{lllllc}
\hline Measure & Abnormal & Normal & Difference & $\mathbf{p}^{*}$ & $\begin{array}{c}\text { Proportion of all children } \\
\text { with abnormal value (\%) }\end{array}$ \\
\hline $\mathrm{HB}$ & 1.77 & 0.72 & 1.05 & 0.009 & 6 \\
$\mathrm{MCV}$ & 1.08 & 0.79 & 0.30 & 0.114 & 10 \\
$\mathrm{MCH}$ & 2.04 & 0.73 & 1.30 & 0.006 & 6 \\
$\mathrm{ZPP}>80$ & 0.78 & 0.83 & 0.05 & 0.952 & 23 \\
$\mathrm{ZPP}>97$ & 1.36 & 0.75 & 0.61 & 0.075 & 10 \\
$\mathrm{Hb}$ or MCH low & 1.73 & 0.55 & 1.18 & $<0.001$ & 9.5 \\
$\mathrm{Hb}$ or MCH low or 2/3 & 2.04 & 0.36 & 1.68 & $<0.001$ & 12 \\
other markers abnormal & & & & & \\
\hline & & & & &
\end{tabular}

was calculated using only the other four markers, to maximise the number of children who could be included in the analysis. The TRS on average also showed a net gain but with a wide range (table 3); $64 \%$ of children had a TRS greater than 0 with $49 \%$ greater than 1 . The TRS was no higher in those receiving 6 as opposed to 3 weeks treatment.

Children with a haemoglobin or MCH below the screening cut off showed the largest therapeutic response to iron (table 4). Children with values above the screening threshold for ZPP (80) did not generally show a therapeutic response to iron. However those above a higher threshold of 97, found in $10 \%$ of the original cohort, did show a reasonable response. Some 44 children had either a low haemoglobin or a low $\mathrm{MCH}$ or both, and they showed a median TRS of 1.18. A further 11 children had abnormal values for two or more of the remaining three measures. All these children together showed a median TRS of 1.68. The remaining 70 children who had normal haemoglobin, MCH, and only one other marker abnormal, showed a median TRS of only 0.36 . In the original screened population as a whole, $13 \%$ of children had abnormal haemoglobin or MCH or abnormal levels of two or more of the remaining three markers and could be defined as iron deficient.

Rates of iron deficiency were slightly higher in the more deprived children, infants introduced to cows' milk before 12 months, and those starting solids or continuing breast feeding after the age of 4 months, and much higher in a small group of infants from an ultra Orthodox Jewish group ( $3 \%$ cohort) with very different feeding patterns from the majority population. However, only the latter two factors were independently statistically significant (table 5). Children with iron deficiency were slightly lighter (mean difference -0.16 ) and shorter (mean difference -0.22 ), but the differences were not significant $(p=0.25$ and 0.14 , respectively).

\section{DISCUSSION}

The diagnosis of severe iron deficiency is straightforward when a low haemoglobin is accompanied by microcytosis and hypochromia. The difficulty is interpreting low markers in isolation, particularly if the haemoglobin is normal. Our findings reinforce the importance of a low haemoglobin and, unexpectedly $\mathrm{MCH}$, as specific markers of iron deficiency in this age group. However, these are still insensitive, as alone each only identified half the children who showed a substantial treatment response. The MCV and ZPP were much less specific, but when both were abnormal these also produced a substantial therapeutic response, even if the haemoglobin and MCH were within normal limits. Ferritin correlated only weakly with the other markers probably because of its strong tendency to rise in the presence of any infection. Zinc protoporphyrin is not often used clinically and initially seemed highly non-specific, but it became apparent that we used different assay techniques from the NDNS, on which our original threshold was based. ${ }^{4}$ Using the more extreme threshold ZPP proved a fair predictor, as has been suggested previously, ${ }^{10}$ and certainly better than ferritin.

The purpose of the study was to study change over time within the cohort, rather than describe the prevalence of iron deficiency, so it was not a major problem that less than half the cohort agreed to take part, due mainly to parental reluctance to distress their child. However, though those who did take part were slightly more affluent, they were still broadly representative of the general population.

The challenge to any study of iron deficiency is the absence of a gold standard test, and a therapeutic response to iron is theoretically the best indicator. Abnormal test results will always tend to improve on re-measurement, but the TRS, by standardising and combining responses, allows comparison both of the size of the response and the extent to which other markers have changed.

Table 5 Association between dietary and social factors and iron deficiency

\begin{tabular}{|c|c|c|c|c|c|c|}
\hline & \multicolumn{4}{|l|}{ Univariate } & \multicolumn{2}{|l|}{ Multivariable* } \\
\hline & Yes & No & Crude OR & pt & Adjusted OR & pł \\
\hline Deprived & $15.7 \%(34)$ & $10.6 \%(26)$ & 1.56 & 0.07 & & \\
\hline Weaned $>4$ months & $21.6 \%(8)$ & $11.4 \%(32)$ & 2.14 & 0.074 & & \\
\hline Breast fed $>4$ months & $24.4 \%(19)$ & $10.7 \%(41)$ & 2.69 & 0.002 & 2.44 & 0.005 \\
\hline Cows' milk $<12$ months & $14.8 \%(18)$ & $12.4 \%(42)$ & 1.23 & 0.30 & & \\
\hline Ultra Orthodox Jewish§ & $57 \%(4)$ & $12.3 \%(56)$ & 9.52 & 0.007 & 6.99 & 0.015 \\
\hline \multicolumn{7}{|c|}{$\begin{array}{l}\text { *Logistic regression, all variables } p<0.1 \text { on univariate analysis added initially, then only variables } p<0.05 \text { left in } \\
\text { model. } \\
+\chi^{2} \text { test. } \\
\text { †Logistic regression. } \\
\S A \text { small group of families with weaning and other feeding practices very different from the remainder of the } \\
\text { cohort. } \\
\text { Values are proportion (number) iron deficient. }\end{array}$} \\
\hline
\end{tabular}


Compliance with iron therapy is a major problem in clinical practice and it is difficult to estimate how good it was in this cohort. Some $40 \%$ percent of the children received only 3 weeks of treatment but showed no difference in response to those receiving the full course. An unexpected finding was the high rates of diarrhoea, particularly in those not completing their treatment course, and this possibly relates to the use of sorbitol as a sweetening agent.

This population showed a much lower prevalence of anaemia than a previous study in Bristol, ${ }^{5}$ although their mean ferritin levels were higher. The Bristol study used capillary sampling, which recent work suggests may substantially underestimate true haemoglobin levels. ${ }^{6}$ We also found slightly lower rates of anaemia than the $\mathrm{NDNS}^{4}$ but in our study the children were 5 months younger and the majority had only recently stopped formula milk, which is strongly fortified with iron. Because of the relatively low prevalence, we had limited power to explore possible risk factors. We found little association between iron deficiency and early consumption of cows' milk, unlike an intervention study where deferring unmodified cows' milk until after the age of a year had a significant effect in preventing iron deficiency. ${ }^{2}$ We found only a weak non-significant trend towards higher rates of iron deficiency in children from the more deprived families, which is in keeping with the NDNS. ${ }^{4}$ We did find an excess of iron deficiency in the minority of children breast fed for more than 4 months, which mirrors the findings of a recent trial ${ }^{11}$ and further endorses the recommendation that breast fed infants need additional sources of iron after the age of 6 months. ${ }^{12}$

\section{CONCLUSIONS}

These findings suggest that in toddlers low haemoglobin or low MCH are highly specific for iron deficiency and should always merit treatment. Low MCV, high ZPP, and possibly low ferritin levels if found in combination also merit treatment, even if the haemoglobin and $\mathrm{MCH}$ are normal, but not if found in isolation. Diarrhoea is a common side effect of iron treatment that may limit parental compliance.

\section{ACKNOWLEDGEMENTS}

Our thanks to Alison Smith, Jane Jarvis, and Ann Pattison for their work on the study, to Philip Lowe for computing support, to John
Barker and his laboratory staff, and to John McColl for helpful discussion of the data. The study would not have been possible without the invaluable support of the midwives at the Gateshead and Newcastle maternity units, the health visitors of Gateshead, and the loyal participation of all the parents.

\section{Authors' affiliations}

C M Wright, Department of Child Health, University of Glasgow, Glasgow, UK

J Kelly, A Trail, K N Parkinson, Department of Child Health, University of Newcastle Upon Tyne, Newcastle Upon Tyne, UK

G Summerfield, Department of Haematology, Queen Elizabeth Hospital, Gateshead, UK

Grant support was provided by Sport Aiding Research in Kids (SPARKS) and the Henry Smith Charity.

Conflict of interest: none declared.

\section{REFERENCES}

1 Aukett MA, Parks YA, Scott PH, et al. Treatment with iron increases weight gain and psychomotor development. Arch Dis Child 1986;61:849-57

2 Daly A, MacDonald A, Aukett A, et al. Prevention of anaemia in inner city toddlers by an iron supplemented cows' milk formula. Arch Dis Child 1996;75:9-16.

3 Moy R, Aukett A. Population screening for anaemia in the inner city. Ambul Child Health 2000;6:11-8.

4 Gregory J, Collins D, Davies P, et al. National Diet and Nutrition Survey: children aged 1.5 to 4.5 years. London: HMSO, 1995.

5 Sherriff A, Emond A, Hawkins N, et al. Haemoglobin and ferritin concentrations in children aged 12 and 18 months. Arch Dis Child 1999:80:153-7.

6 Moy RJD. Over-estimation of the prevalence of iron deficiency anaemia by screening with the HemoCue haemoglob (eLetter). Arch Dis Child 2001. http://adc.bmijournals.com/cgi/eletters/84/6/480 (accessed 13 August 2004).

7 Walter T, Kovalskys J, Stekel A. Effect of mild iron deficiency on infant mental development scores. J Pediatrics 1983;102:519-22.

8 Freeman JV, Cole TJ, Chinn S, et al. Cross sectional stature and weight reference curves for the UK, 1990. Arch Dis Child 1995;73:17-24.

9 Preece M, Freeman J, Cole T. Sex differences in weight in infancy: published centile charts have been updated. BMJ 1996;313:1486.

10 Siegel RM, LaGrone DH. The use of zinc protoporphyrin in screening young children for iron deficiency. Clin Pediatr (Phila) 1994;33:473-9.

11 Dewey K, Cohen R, Rivera L, et al. Effects of age of introduction of complementary foods on iron status of breast-fed infants in Honduras. Am J Clin Nutr 1998;67:878-84

12 Committee on Medical Aspects of Food, Department of Health. Weaning and the weaning diet. London: HMSO, 1994:45.

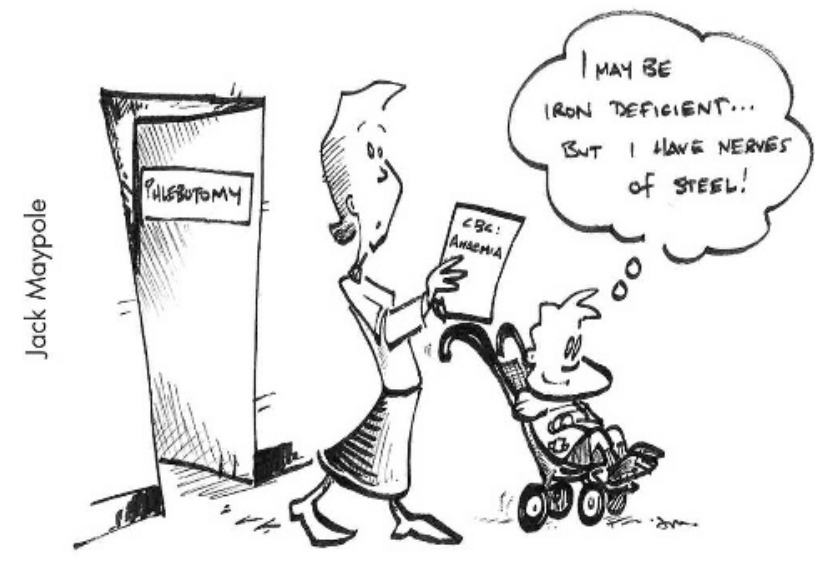

